\title{
Estimativa da concentração espermática do sêmen de peixe pelo método de espermatócrito
}

\section{Eduardo Antônio Sanches ${ }^{1}$, Ronan Maciel Marcos², Diego Mendes Baggio², Lucélia Tessaro², Rafael Ernesto Balen ${ }^{3}$, Robie Allan Bombardelli ${ }^{2}$}

\footnotetext{
${ }^{1}$ Centro de Aqüicultura, Universidade Estadual Paulista Júlio de Mesquita Filho.

2 Centro de Engenharias e Ciências Exatas, Universidade Estadual do Oeste do Paraná.

${ }^{3}$ Departamento de Zoologia, Universidade Federal do Paraná.
}

RESUMO - Um experimento foi realizado com o objetivo de estimar a concentração espermática das espécies dourado (Salminus brasiliensis), curimba (Prochilodus lineatus), jundiá (Rhamdia quelen), cascudo-preto (Rhinelepis aspera) e tilápia-do-nilo (Oreochromis niloticus) pelo método de espermatócrito. Utilizaram-se 19, 58, 51, 43 e 85 reprodutores de dourado, curimba, jundiá, cascudo-preto e tilápia-do-nilo, respectivamente. Com exceção da tilápia-do-nilo, os reprodutores foram submetidos ao processo de indução hormonal e posteriormente submetidos a coleta de sêmen. Foram comparadas as técnicas de mensuração da concentração espermática do sêmen por contagem em câmara hematimétrica de Neubauer e por espermatócrito. Os resultados obtidos foram submetidos à análise de regressão a 5\% de probabilidade. As concentrações espermáticas mensuradas por ambas as técnicas apresentaram relação linear, para curimbas, jundiás e tilápias-do-nilo, com equações y $=6,6624 \times 10^{9}+3,68553 \times 10^{8} \mathrm{x} ; \mathrm{y}=2,153 \times 10^{9}+4,426 \times 10^{8} \mathrm{x}$ e $\mathrm{y}=-9,0897 \times 10^{8}+6,0167 \times 10^{8}$, respectivamente. O método de espermatócrito pode ser utilizado para estimar a concentração espermática do sêmen de curimbas, jundiás e tilápias-do-nilo.

Palavras-chave: Oreochromis niloticus, Prochilodus lineatus, reprodução de peixes, Rhamdia quelen, Rhinelepis aspera, Salminus brasiliensis

\section{Sperm concentration estimate of fish semen using spermatocrit method}

\begin{abstract}
The objective of this experiment was estimate sperm concentration of "dourado" (Salminus brasiliensis), “curimba” (Prochilodus lineatus), “jundiá” (Rhamdia quelen), “cascudo-preto” (Rhinelepis aspera) and Nile tilapia (Oreochromis niloticus) by the method of spermatocrit. It was used 19, 58, 51, 43 and 85 brood fish of "dourado", "curimba”, "jundia", "cascudo-preto" and Nile tilapia, respectively. Except for the Nile tilapia, the fishes were subjected to the hormonal induction process and then submitted to the semen collection. The measurement techniques of the sperm concentration by sperm count in Neubauer chamber (CSPZ) and by spermatocrit (ESPMT) were compared. The results were submitted to the regression analysis at $5 \%$ of probability. It was observed that the variables CSPZ and ESPMT presented linear relationship to the "curimba", "jundia" and Nile tilapia with equations $y=6.6624 \times 10^{9}+368553 \times 10^{8} \mathrm{x}$; y $=2.153 \times 10^{9}+4.426 \times 10^{8} \mathrm{x}$ and $\mathrm{y}=-9.0897 \times 10^{8}+6.0167 \times 10^{8}$, respectively. The method of spermatocrit can be used to estimate the sperm concentration of "curimba”, “jundiá” and Nile tilapia.
\end{abstract}

Key Words: fish reproduction, Oreochromis niloticus, Prochilodus lineatus, Rhamdia quelen, Rhinelepis aspera, Salminus brasiliensis

\section{Introdução}

$\mathrm{Na}$ rotina de reprodução artificial de peixes, a determinação de alguns parâmetros quantitativos, como a concentração espermática, é fundamental, pois permite controlar e otimizar as taxas de fertilização e, consequentemente, promover o uso racional de reprodutores em sistemas de cultivo. Essa racionalização pode ser obtida com o emprego de relações adequadas entre espermatozoides:ovócitos (Bombardelli et al., 2006). Além disso, pode servir como ferramenta para manter animais com grande produção de gametas e definir o momento da recomposição dos estoques de reprodutores (Rurangwa et al., 1998).

Uma das metodologias comumente empregadas para avaliação da concentração espermática de peixes é a contagem de espermatozoides em câmara hematimétrica de Neubauer (Streit Junior et al., 2003; Wirtz \& Steinmann, 2006). Contudo, 
métodos alternativos que envolvem maior praticidade e rapidez, menores custos com materiais e equipamentos e não necessitem de tratamento prévio do sêmen com diluidores ou fixadores podem ser empregados, como a determinação da concentração espermática por meio do espermatócrito (Rakitin et al., 1999; Tvedt et al., 2001). Este é um método de mensuração indireta da concentração espermática, servindo como ferramenta auxiliar na avaliação de sêmen, podendo ser empregado em condições de campo (Kavamoto et al., 1986). Consiste na centrifugação do sêmen, em microtubos capilares preenchidos com aproximadamente $70 \%$ de fluido seminal e vedados em uma das extremidades. Após a centrifugação ocorre à separação do plasma seminal das células espermáticas e, através do acúmulo celular, é determinado o percentual de espermatozoides presente no sêmen por meio de um padrão gráfico (Borges et al., 2005).

Diante disso, realizou-se este experimento com o objetivo de estimar a concentração espermática do dourado (Salminus brasiliensis), curimba (Prochilodus lineatus), jundiá (Rhamdia quelen), cascudo-preto (Rhinelepis aspera) e tilápia-do-nilo (Oreochromis niloticus) pelo método do espermatócrito.

\section{Material e Métodos}

O trabalho foi conduzido no Laboratório de Tecnologia da Reprodução dos Animais Aquáticos Cultiváveis (LATRAAC)/UNIOESTE, instalado no Centro de Pesquisas em Aqüicultura Ambiental (CPAA) do Instituto Ambiental do Paraná (IAP) - Toledo, Paraná. Foram utilizados 19 reprodutores de dourado, 53 de curimba, 51 de jundiá, 43 de cascudo-preto e 85 de tilápia-do-nilo. Os reprodutores foram provenientes da própria estação de criação, onde estavam estocados em tanques escavados de $200 \mathrm{~m}^{2}$, revestidos com concreto e com fundo de terra. Os reprodutores de dourado apresentavam aproximadamente 3 anos de idade e, durante o período antecedente à coleta, foram alimentados com peixes forrageiros. Os reprodutores de curimba e cascudo-preto tinham aproximadamente 3 e 15 anos, respectivamente, e foram alimentados basicamente com substrato e ração extrusada comercial contendo $28 \%$ de PB. As tilápias-do-nilo e os jundiás tinham 2 anos de idade e foram alimentadas com ração peletizada contendo $35 \%$ de PB.

A seleção dos reprodutores foi realizada dentro do tanque de criação durante o período reprodutivo, de novembro de 2005 a fevereiro de 2006. Foram selecionados machos que liberavam esperma sob leve pressão abdominal. Os animais selecionados foram transferidos ao laboratório, onde foram individualmente marcados, pesados e separados em caixas circulares de $1.500 \mathrm{~L}$, com renovação constante de água, por meio de bombeamento, proveniente de um tanque da própria estação.

Com o intuito de aumentar a produção seminal, aplicou-se uma dose única de extrato pituitário de carpa (EPC) de forma intramuscular, nas dosagens de 2,5; 5,5; 3,0 e 5,5 mg.kg de reprodutor ${ }^{-1}$ para dourado, curimba, jundiá e cascudo-preto, respectivamente (adaptado de Zaniboni Filho \& Weingartner, 2007). Após as aplicações hormonais nos peixes, a temperatura da água foi monitorada a cada hora. Os reprodutores de tilápia-do-nilo não foram submetidos ao processo de indução hormonal.

A coleta dos gametas masculinos foi realizada após um período de 160 horas-grau (somatória da temperatura da água em função do tempo após a indução hormonal), para o dourado e o curimba e de 240 UTA para o jundiá e cascudopreto. Para as coletas do sêmen, os animais foram contidos e secos com pano e papel-toalha. Com a garantia de que a papila genital estava seca, foi aplicada individualmente massagem na região ventral do animal sempre no sentido céfalo-caudal. A primeira gota de sêmen foi desprezada para evitar possível contaminação com urina (Poupard et al., 1998), o restante do sêmen foi coletado até a redução na liberação, evitando-se qualquer sinal de sangramento, a fim de impedir contaminação e influências na mensuração do espermatócrito. A coleta foi realizada individualmente em um tubo Falcon de 10,0 mL \pm 0,1 mL, para mensuração do volume total liberado. O sêmen de tilápia-do-nilo foi coletado em uma seringa de insulina de $1,0 \mathrm{~mL} \pm 0,01 \mathrm{~mL}$.

A mensuração da concentração espermática do sêmen foi realizada de forma individual a partir do sêmen proveniente de cada reprodutor, utilizando-se os métodos de contagem de espermatozoides em câmara hematimétrica de Neubauer, espermatozoides.mL - $^{-1}$ (Wirtz \& Steinmann, 2006), e pela medida de espermatócrito, em \% (Rideout et al., 2004).

Para a mensuração da concentração espermática em câmara hematimétrica de Neubauer, utilizou-se uma amostra de $5 \mu \mathrm{L}$ de sêmen, que foi diluída em $5.000 \mu \mathrm{L}$ de formol salina tamponado (Streit Junior et al., 2004a), resultando na diluição de 1:1000. Com o material diluído, realizou-se a contagem de células espermáticas presentes em dez campos da câmara hematimétrica de Neubauer (Streit Junior et al., 2003; Bombardelli et al., 2006). A concentração espermática foi calculada de forma semelhante ao recomendado pelo CBRA (1998) para mamíferos, segundo a equação:

$$
\operatorname{CSPZ}\left(S P Z . m L^{-1}\right)=\left(\frac{\sum S P Z}{10 \text { q.c. }}\right) \times \frac{25 \text { q.t. } \times \text { diluição } \times 1000}{\text { profundidade da câmara }(\mathrm{mm})}
$$

em que SPZ = espermatozoides; $\Sigma \mathrm{SPZ}=$ número total de espermatozoides contados; q.c. = quadrículas contadas; 
q.t. = quadrículas totais; profundidade da câmara $=0,10 \mathrm{~mm}$ e diluição = fator de diluição do sêmen pelo fixador.

A mensuração do espermatócrito foi realizado utilizando-se tubos capilares de micro-hematócrito, preenchidos com aproximadamente $70 \%$ de sêmen e vedados em uma das extremidades. Em seguida, os tubos foram submetidos à centrifugação por 15 minutos a 12.000 rotações.minuto-1 ${ }^{-1}$ em uma microcentrífuga. Após a centrifugação, realizou-se a medida do percentual de massa celular presente no sêmen com uma régua hematimétrica.

Para verificar a existência de possíveis relações entre as concentrações espermáticas determinadas em câmara de Neubauer e pelo espermatócrito, os resultados foram submetidos à análise de regressão linear simples a 5\% de probabilidade. O software utilizado para as análises estatísticas foi o Statistica $7.0{ }^{\circledR}$.

\section{Resultados e Discussão}

Em comparação a outros trabalhos, o sêmen coletado dos reprodutores utilizados no experimento (Tabela 1) apresentou características quantitativas satisfatórias, e isso sugere que os peixes estavam em adequadas condições reprodutivas. Sanches et al. (2009) verificaram para o Salminus brasiliensis volume seminal de 7,24 \pm 5,18 e $12,32 \pm 1,90 \mathrm{~mL}$ e concentração de espermatozoides de 7,52 e $7,58 \times 10^{9} \cdot \mathrm{mL}^{-1}$. Streit Junior et al. (2004b) observaram a liberação de $0,45 \mathrm{~mL}$ e concentração de espermatozoides de $1,4 \times 10^{10} . \mathrm{mL}^{-1}$ para o Prochilodus lineatus. Bombardelli et al. (2006) verificaram para o Rhamdia quelen $5,9 \pm 0,54 \mathrm{~mL}$ e $1,97 \times 10^{10} \cdot \mathrm{mL}^{-1}$. Para Oreochromis niloticus, foram

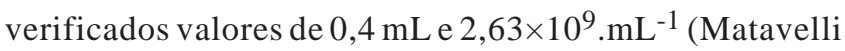
et al., 2007), 0,19 a $0,47 \mathrm{~mL}$ e 3,08 a $8,19 \times 10^{9} \cdot \mathrm{mL}^{-1}$ (Bombardelli, et al., 2010).

Algumas características quantitativas do sêmen dos reprodutores deste estudo (Tabela 1) são diferentes das observadas em outros trabalhos, no entanto, essas diferenças são normalmente evidenciadas em peixes teleósteos (Godinho, 2007), uma vez que a produção seminal é influenciada por diversos fatores, como o método de coleta a partir da extrusão, que não garante a liberação do volume total de sêmen presente nas gônadas (Ferreira et al., 2001). Além disso, outros fatores são responsáveis pela variação dessa produção, entre eles, o tamanho do indivíduo (Luz et al., 2001); a idade dos reprodutores (Bastardo et al., 2004); a realização de coletas seminais sucessivas (Kavamoto et al., 1997); a realização de indução hormonal e os hormônios aplicados durante o processo (Zaniboni Filho \& Weingartner, 2007) e a época do ano (Borges etal., 2005).

Observou-se relação linear $(\mathrm{P}<0,05)$ entre a concentração espermática determinada em câmara de Neubauer e pelo espermatócrito para o curimba (Figura 1), o jundiá (Figura 2) e tilápia-do-nilo (Figura 3). Esses resultados sugerem que a análise de concentração espermática do sêmen dessas espécies pode ser realizada pelo método do espermatócrito, cujas análises são mais rápidas e práticas, em substituição à câmara hematimétrica de Neubauer.

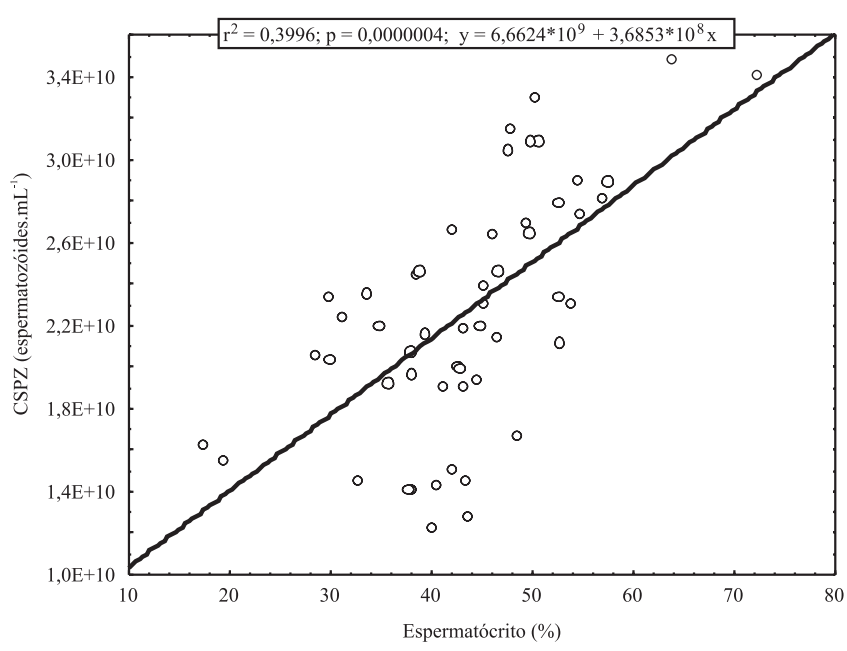

Figura 1 - Relação entre a concentração espermática mensurada por contagem em câmara hematimétrica de Neubauer e espermatócrito do sêmen de curimba (Prochilodus lineatus).

Tabela 1 - Peso corporal, volume de sêmen e concentração espermática determinada em câmara de neubauer e por espermatócrito em dourado, curimba, jundiá, cascudo-preto e tilápia-do-nilo

\begin{tabular}{lrrrrr}
\hline Variável & \multicolumn{4}{c}{ Espécie } \\
\cline { 2 - 5 } & Dourado & Curimba & Jundiá & Cascudo-preto Tilápia-do-nilo \\
\hline Número de reprodutores & 19 & 53 & 51 & 43 & 85 \\
Peso (kg) & $0,76 \pm 0,27$ & $0,72 \pm 0,36$ & $0,11 \pm 0,03$ & $1,14 \pm 0,18$ & $0,25 \pm 0,05$ \\
Volume de sêmen coletado (mL) & $8,72 \pm 4,42$ & $2,80 \pm 2,11$ & $3,92 \pm 2,27$ & $9,91 \pm 9,23$ & $0,30 \pm 0,34$ \\
Concentração espermática & & & & \\
Câmara de Neubauer (espermatozoides $\times 10^{10} \cdot \mathrm{mL}^{-1}$ ) & $1,29 \pm 0,37$ & $2,27 \pm 0,58$ & $1,79 \pm 0,46$ & $2,10 \pm 0,37$ & $0,52 \pm 0,42$ \\
Espermatócrito (\%) & $15,84 \pm 3,93$ & $43,43 \pm 9,90$ & $35,52 \pm 8,85$ & $60,52 \pm 11,18$ & $9,33 \pm 4,31$ \\
\hline
\end{tabular}




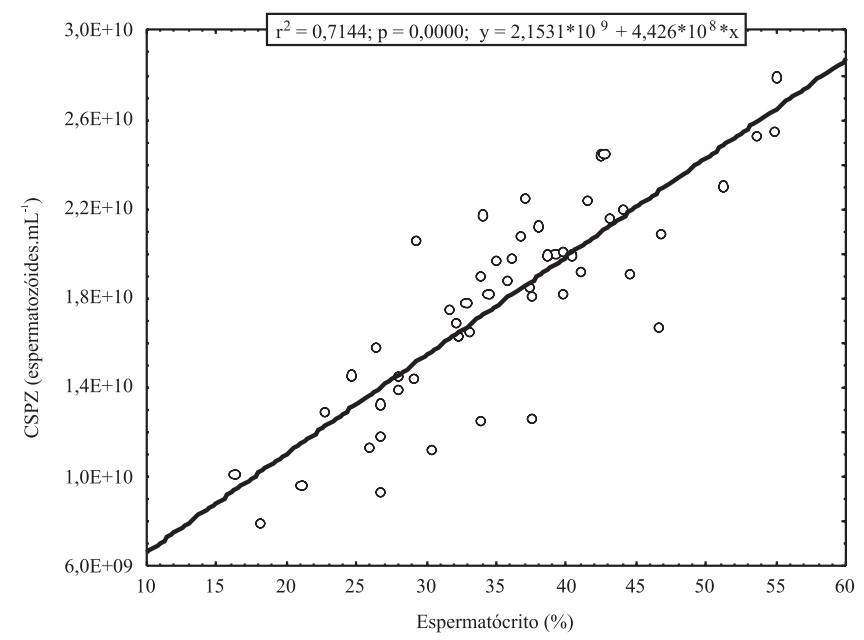

Figura 2 - Relação entre a concentração espermática mensurada por contagem em câmara hematimétrica de Neubauer e espermatócrito do sêmen de jundiá (Rhamdia quelen).

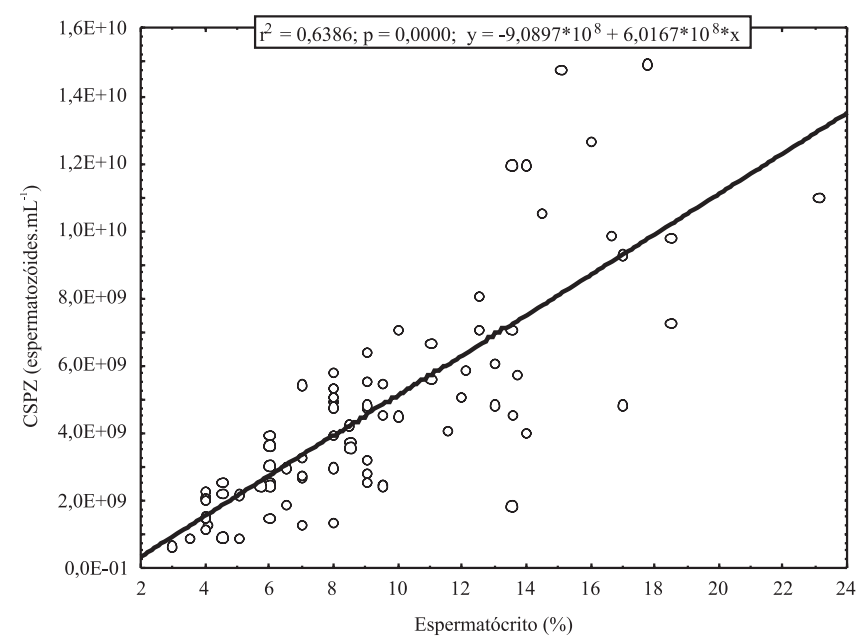

Figura 3 - Relação entre a concentração espermática determinada por contagem em câmara hematimétrica de Neubauer e espermatócrito do sêmen de tilápia-do-nilo (Oreochromis niloticus).

O estudo da viabilidade do uso da mensuração da concentração espermática através do uso do espermatócrito também foi empregado com sucesso para outras espécies, como o Rhamdia quelen (Borges et al., 2005), Prochilodus scrofa (Kavamoto et al., 1986), Salmo irideus (Bastardo et al., 2004), Hippoglossus hippoglossus (Tvedt et al., 2001), Gadus morhua (Rakitin et al., 1999), Salmo trutta (Poople \& Dillane, 1998) e Melanogrammus aeglefinus (Rideout et al., 2004). Esses autores também indicam que o espermatócrito pode ser o método de mensuração da concentração espermática destas espécies, sendo, além de barato, rápido e eficiente.
Não foi observada relação $(\mathrm{P}>0,05)$ entre a concentração espermática determinada em câmara de Neubauer e pelo espermatócrito para o dourado e cascudo-preto. Esse resultado sugere que a análise de concentração espermática do sêmen dessas espécies não pode ser realizada pelo método do espermatócrito. Estes resultados podem ter recebido influências de outras células liberadas junto com o sêmen, como por exemplo, fragmentos de epitélio gonadal e até mesmo hemácias proveniente de possíveis ações hemorrágicas, não evidenciadas no momento da coleta seminal. Além disso, o processo de centrifugação aplicado pode não ser o ideal para estas espécies, pois o tempo e a velocidade de centrifugação influenciam diretamente nos resultados da leitura do espermatócrito (Tvedt et al., 2001; Borges et al., 2005).

Rakitin et al. (1999) analisaram a concentração espermática em bacalhau do atlântico pela contagem em câmara de Neubauer, observaram algumas agregações de espermatozoides na área de leitura. Essas agregações foram resultado de uma ineficiente diluição espermática, devido principalmente aos pequenos volumes de sêmen e diluidor utilizados no processo. Ainda, estes autores encontraram relação linear entre o espermatócrito e a concentração espermática pelo método eletrônico de analisador de partículas “Coulter Multisizer”, no entanto, não foi evidenciada a relação entre os resultados de espermatócrito e a contagem de células espermáticas em câmara de Neubauer, possivelmente devido aos problemas de diluição.

\section{Conclusões}

O método de espermatócrito pode ser recomendado para condições laboratoriais e de campo para peixes como o curimba (Prochilodus lineatus), jundiá (Rhandia quelen) e tilápias-do-nilo (Oreochromis niloticus).

\section{Referências}

BASTARDO, H.; GUEDEZ C.; LEÓN, M. Características del semen de trucha arcoiris de diferentes edades, bajo condiciones de cultivo en Mérida, Venezuela. Zootecnia Tropical v.22, n.3, p.277-288, 2004.

BOMBARDELLI, R.A.; MÖRSCHBÄCHER, E.F.; CAMPAGNOLO, R. et al. Dose inseminante para fertilização artificial de ovócitos de jundiá Rhamdia quelen (Quoy \& Gaimardm, 1824). Revista Brasileira de Zootecnia, v.35, n.4, p.1251-1257, 2006.

BOMBARDELLI, R.A.; HAYASHI, C.; NATALI, M.R.M. et al. Níveis de energia digestível sobre desempenho reprodutivo e zootécnico e a deposição de lipídios nos hepatócitos de machos de tilápia-do-nilo. Revista Brasileira de Zootecnia, v.39, n.5, p.941-949, 2010.

BORGES, A.; SIQUEIRA, D.R.; JURINITZ, D.F. et al. Biochemical composition of seminal plasma and annual variations in semen 
characteristics of jundiá Rhamdia quelen (Quoy \& Gaimard, Pimelodidae). Fish Physiology and Biochemistry, v.31, p.45-53, 2005.

COLÉGIO BRASILEIRO DE REPRODUÇÃO ANIMAL - CBRA. Manual para exames andrológicos e avaliação de sêmen animal. 2.ed. Belo Horizonte: Colégio Brasileiro de Reprodução Animal, 1998. 49p.

FERREIRA, A.A.; NUÑER, A.P.O.; LUZ, R.K. et al. Avaliação qualitativa e quantitativa do sêmen de jundiá, Rhamdia quelen. Boletim do Instituto de Pesca, v.27, n.1, p.57-60, 2001.

GODINHO, H.P. Estratégias reprodutivas de peixes aplicadas à aqüicultura: bases para o desenvolvimento de tecnologias de produção. Revista Brasileira de Reprodução Animal, v.31, n.3, p.351-360, 2007.

KAVAMOTO, E.T.; FOGLI DA SILVEIRA, W.; GODINHO, H.M. Características Seminais do Curimbatá, Prochilodus scrofa STEINDACHNER, 1881. Boletim do Instituto de Pesca, v.13, n.2, p.45-50, 1986.

KAVAMOTO, E.T.; MAINARDES-PINTO, C.S.R.; ANDRADE TALMELLI, E.F. et al. Produção espermática do curimbatá Prochilodus scrofa.Steindachner, 1881, Boletim do Instituto de Pesca, v.24, n.único, p.73-78, 1997.

LUZ, R.K.; FERREIRA, A.A.; REYNALTE-TAJATE, D.A. et al. Avaliação qualitativa e quantitativa do sêmen do suruvi, Steindachneridion scripta (pimelodidae). Boletim do Instituto de Pesca, v.27, n.1, p.39-42, 2001.

MATAVELLI, M.; MORAES, G.V.; STREIR JUNIOR, D.P. et al. Avaliação da qualidade do sêmen de tilápia-do-nilo (Oreochromis niloticus), linhagem chitralada, suplementada com diferentes concentrações de vitamina C. Boletim do instituto de Pesca, v.33, n.1, p.1-7, 2007.

POOPLE, W.R.; DILLANE, M.G. Estimation of sperm concentration of wild and reconditioned brown trout, Salmo truta L. Aquaculture Research, v.29, p.439-445, 1998.

POUPARD, G.P.; PAXION, C.; COSSON, J. et al. Initiation of carp spermatozoa motility and early ATP reduction after milt contamination by urine. Aquaculture, v.160, p.317-328, 1998.

RAKITIN, A.; FERGUSON, M.M.; TRIPPEL, E.A. Spermatocrit and spermatozoa density in Atlantic cod Gadus morhua: correlation and variation during the spawning season. Aquaculture, v.170, p.349-358, 1999.

RIDEOUT, R.M.; TRIPPEL, E.A.; LITVAK, M.K. Relationship between sperm density, spermatocrit, sperm motility and spawning date in wild and cultured haddock. Journal of Fish Biology, v.65, p.319-332, 2004.

RURANGWA, E.; ROELANTS, I.; HUYSKENS, G. et al. The minimum effective spermatozoa:egg ratio for artificial insemination and the effects of mercury on sperm motility and fertilization ability in (Clarias gariepinus). Journal of Fish Biology, v.53, p.402-413, 1998.

SANCHES, E.A.; BOMBARDELLI, R.A.; BAGGIO, D.M. et al. Dose inseminante para fertilização artificial de ovócitos de dourado. Revista Brasileira de Zootecnia v.38, n.11, p.2091-2098, 2009.

STREIT JUNIOR, D.P.; MORAES, G.V.; RIBEIRO, R.P. et al. Avaliação de diferentes técnicas para coloração de sêmen de peixes. Arquivos de Ciências Veterinárias e Zoologia. UNIPAR, v.7, n.2, p.157-162, 2004a.

STREIT JUNIOR, D.P.; MORAES, G.V.; RIBEIRO, R.P. et al. Comparação do sêmen de Curimbá (Prochilodus lineatus) induzido por extrato de hipófise de frango, coelho ou carpa, Brazilian Journal of Veterinary and Animal Science, v.41, p.147-153, 2004b.

STREIT JUNIOR, D.P.; MORAES, G.V.; RIBEIRO, R.P.R. et al. Estudo comparativo da indução hormonal da espermiação em piavuçu (Leporinus macrocephalus) com extrato de hipófise de frango, coelho e carpa. Acta Scientiarum.Animal Sciences, v.25, n.2, p.261-266, 2003.

TVEDT, H.B.; BENFEY, T.J.; MARTIN-ROBICHAUD, D.J. et al. The relationship between sperm density, spermatocrit, sperm motility and fertilization success in Atlantic halibut, hippoglossus hippoglossus. Aquaculture, v.194, p.191-200, 2001.

WIRTZ, S.; STEINMANN, P. Sperm characteristics in perch Perca fluviatilis L. Journal of Fish Biology, v.68, p.1896-1902, 2006.

ZANIBONI FILHO, E.; WEINGARTNER, M. Técnicas de indução da reprodução de peixes migradores. Revista Brasileira de Reprodução Animal, v.31, n.3, p.367-373, 2007. 